\title{
The Constraints Experienced by Educational Officials during the Implementation of Technology Education in North West Province, South Africa
}

\author{
Gumbo MT \\ University of South Africa
}

\author{
Tholo JAT \\ Department of Education North West
}

\begin{abstract}
The implementation of Technology Education is an under researched area. This paper reports the findings of a qualitative study that was conducted in the North West Province of South Africa to gather the views of education officials about the implementation of Technology Education. Technology Education is still a relatively newcomer that was, for the first time ever, included in the South African curriculum transformation at the dawn of democratic governance around 1994. Its inclusion was inspired by the global trends that motivated Technology Education as a school subject. But the implementation of Technology Education in South Africa has not been without constraints. In order to understand the constraints that plagued the implementation of the subject, a study was conducted in which fifteen Technology Education officials, who comprised seven Heads of Departments (HoDs), four subject experts and four subject advisors were interviewed using semi-structured interviews. These officials were responsible for managing the implementation of Technology Education at Grade 7-9 schools in North West Province. The findings revealed the following constraints to the implementation of Technology Education: unsatisfactory teacher training, lack of resources and factors impacting on the Technology Education pedagogy. We believe that at practice level Technology Education curriculum planners and implementers should take into account these hindrances in order to ensure the successful implementation of Technology Education. Theoretically this paper contributes to the scarce body of knowledge in the field of Technology Education curriculum implementation.
\end{abstract}

\section{Introduction}

Technology is the use of knowledge, skills and resources to meet human needs and wants or solve practical problems across all cultures whilst being sensitive to its impact and consequences on the environment [1]. Technology is also defined as the human activity that transforms the natural environment to make it fit better with human needs, thereby using various kinds of information and knowledge, various kind of natural (materials, energy) and cultural resources (money, social relationships, etc.) [2]. The daily practical influence of technology on people's lives triggered the recent need to consider Technology Education as a school subject in South Africa [3]. Technology, as it is called in South Africa (but called in different names elsewhere, like Technology Education or Deign and Technology) was introduced in the South African school curriculum in order to produce technologically literate citizenry, specifically "engineers, technicians and artisans needed in modern society" [1]. Technology Education learners are thus envisaged to become innovators and creators of technological solutions, critical thinkers [1]. Learning Technology equips them to manage time and material resources effectively and provides them opportunities for collaborative learning and nurtures teamwork [1]. Fifteen years since its roll-out, the implementation of Technology Education has been plagued by certain constraints [4] particularly when considering that the rate of this implementation was too rapid and not properly resourced [5]. These constraints were exacerbated by lack of qualified teachers in the field to an extent that Department of Basic Education had to ask teachers qualified in other subjects to "try their luck" in Technology Education [6]. This state of affairs triggered this study. We were interested in gathering the views of Technology Education officials about the constraints that they experienced facing its implementation. No other studies have been conducted 
about the implementation of Technology Education which solicited educational officials' views. Education officials are better placed to provide information at seniority level where they operate. As rollers of curriculum in schools, they are perceived to be rich informants who harbor experiences pertaining to the implementation itself. The findings of this study will inform the planning and management of the implementation of Technology Education - will provide an alert about pertinent constraints that have a potential to inhibit the smooth implementation of Technology Education. We proceed by presenting the relevant consulted literature related to the implementation of Technology Education. We then outline the method of data gathering and analysis, present the findings of the study and conclude as well as make relevant recommendations.

\section{The implementation of Technology Education}

The successful implementation of Technology Education depends on a lot of factors which may include planning, resources, teacher supply and preparation, pedagogical aspects, monitoring, and so forth. Building the Capacities of Curriculum Specialists for Educational Reform [7] has identified lack of competent staff and resources as constraints in the project of curriculum implementation. Building the Capacities of Curriculum Specialists for Educational Reform [7] writes that curriculum implementation cannot be ideally executed as a number of factors operate during the process. Thus, the successful implementation of Technology Education means that certain measures should be put in place to counter these constraints.

Teachers should have a solidly established personal construct of technology. Reitsma and Mentz [8], in their needs-analysis study, identified the following aspects that need to be developed in Technology Education teachers:

- Subject content knowledge and skills to be able to function as a knowledgeable person in the learning area technology;

- $\quad$ Pedagogical knowledge and skills to be able to function as a knowledgeable learning area technology teacher in the school environment; and

- Pedagogical content knowledge developed through adequate implementation and support in practice.
This claim is premised on the need to ensure a proper preparation of teachers, which is a critical factor in the implementation of Technology Education. Literature indicates that some of the most important factors in determining whether teachers are adequately equipped to teach Technology successfully are content knowledge and pedagogical skills [9] as revealed above. Content and pedagogical knowledge relate back to Shulman's [10] seminal work in which he developed a seven-part classification on which the teacher knowledge is based - subject matter, pedagogical content, general pedagogy, curriculum, learners and their characteristics, educational contexts and educational aims, and purposes and values. Studies in teacher training argue that teachers seriously lack pedagogical skills [11]. This implicates the professional development that Technology Education teachers should undergo. However, this has not proven to be so in South Africa since the inception of Technology Education in 1998.

As said in the introduction above, due to the lack of trained teachers in the field when Technology Education was first implemented, teachers qualified in other subjects were asked to volunteer to teach Technology. This is because there were no teachers qualified as specialists in Technology Education at the time of rolling out its implementation in 1998. The lack of teachers posed huge implementation challenges to the Department of Education particularly when taking into account that the rate of the implementation was too rapid and not properly resourced [5]. It is noted that this phenomenon was also prevalent in other countries. For instance, in China teachers qualified in non-Technology Education subjects were asked to teach Technology [12].

The underdevelopment of Technology Education teachers in South Africa presents an unfortunate situation, especially when considering attempts by Department of Basic Education to train teachers. Noteworthy is a two-year Advanced Certificate in Education (ACE) that has been running nationally. The ACE is a subject-specific programme that seeks to skill or up-skill teachers in their specialisation subjects. This underdevelopment of Technology Education teachers seems to be further compounded by the limited support that they receive especially from their subject advisors. Department of Basic Education [13] commissioned an appointed Review Committee in 2008/9 to review the National Curriculum Statement. The Review Report revealed amongst other things, that there were too few subject advisors nationwide to offer thorough and 
qualitative in-class support to teachers. The fewness of subject advisors specifically for Technology Education does not come as a surprise to us authors as it logically results from the fact that there were no teachers qualified in Technology Education when it was first rolled out - where, then, would subject advisors qualified in Technology Education come from? The few subject advisors were also appointed with insufficient knowledge and skills to offer the needed support to teachers. For example, Malada [14] found out that there was no tangible and sustainable support given to the Limpopo Province teachers and that school visits by the subject advisors were almost nonexistent. Monitoring and evaluation of the implementation of curriculum policies has been nonexistent in the general curriculum implementation. This would have impacted on the implementation of Technology Education. As a result, there are many questions that remain unanswered about the implementation in question [15].

Another important aspect on which the implementation of Technology Education rests is resources as indicated above from Capacities of Curriculum Specialists for Educational Reform [7]. Bearing in mind the relative newness of Technology Education in the curriculum, its implementation suggests a dire need for (financial, human and physical) resources. Many schools offering Technology Education are still characterised by a fervent need for resources. In their study, Reitsma and Mentz [8] observed a discrepancy between schools with very little resources such as water and electricity only and schools with adequate resources such as computers, libraries and internet access. Schools in a mostly rural North West Province would characterise schools with limited resources. The findings of a study by Williams and Gumbo [16] revealed that the Technology Education subject was not resourced and teachers relied heavily on the use of textbooks as a result. Technology was taught in ordinary classrooms without any technological equipment [17]. Only in one urban school was there a dedicated resourced classroom for Technology Education though it was also an ordinary classroom. Though their studies targeted teachers, this finding is important for purposes of this study - it was envisaged that the educational officials targeted in this study would raise school-based issues as implementation practically happens in schools.

The next section explains the research methods followed in collecting and analysing the data.

\section{Research design and methods}

This study addressed the research question: What are the constraints of the implementation of Technology Education in the Grade 7-9 schools in North West Province?

The one-on-one semi-structured interviews were conducted to explore the individual educational officials' views about the implementation of Technology Education. The approach to semistructured interviews was to ask open-ended questions prepared in interactive and informal ways to elicit responses from the participants [18]. The interviews were recorded with the permission of the officials to allow the collected data to be transcribed for the identification of emerging themes useful for the study [19].

These officials operate at three different levels determined by their specializations. These are Heads of Departments (HoDs), Technology Education Experts (TEEs) and Technology Education Subject Advisors (TESAs). As a result, seven HoDs, four TEEs and four TESAs were approached and selected purposefully. We explained the purpose of our investigation, sought the participants' permission to interview, and promised to treat their participation and information that they gave confidentially, including the concealment of their true names. The seven HoDs were selected due to their theoretical expertise [19] in the subject; the four TEEs were selected due to their experiences or knowledge [20] of the subject; and the four TESAs were selected due to their availability in their offices [21]. Interviews for the HoDs were conducted during their workshops at the Area Project Offices and some in schools where they were based. These interviews lasted about 40 minutes each.

Member-checking was conducted with the officials to ensure credibility of the data. Data analysis, which started during data collection, followed data transcription and coding, topic ordering, constructing themes or categories, reading for content and inserting codes and analysis and interpretation.

\section{Findings}

The themes under which these findings are presented, which surfaced from the analysis, are Technology Education teacher training, resources and factors impeding the pedagogy of Technology Education. These should be understood as the constraints that the educational officials faced during the implementation of Technology Education. In 
presenting the findings we do not specifically give the educational officials' views according to their (officials') categories of specialisation, that is HoDs, TESAs and TEEs. Our reason is that these officials share the implementation experiences because they work closely with each other and report to each other as per the protocol that they should observe.

\subsection{Technology Education teacher training}

A few patterns developed under this theme. The first was the mode of training that was lacking according to the educational officials' views. Their views covered a number of issues under the mode of training - "in-service training is not proper, not intensive and not offered by well qualified trainers"; "workshops and training of teachers is not thorough"; "universities should train teachers"; "expose teachers to industrial environment for a year". All these listed constraints can be understood in the light of a lack of professional workforce - Technology Education teachers, and obviously specialised (trained) educational officials. In the process of interviewing these officials one TESA actually mentioned that he did not have any training background in Technology Education and that what made this worse was the fact that he was allocated an empty office an expected to build it into a Technology Education office. This could confirm that, just like the non existence of teachers specialising in Technology Education when it was rolled out, there was equally no educational officials specialising in this subject as well.

However, the officials had positive views about the efforts that Department of Basic Education had taken to try to address their training needs. Specifically to industrial exposure and universities one participant acknowledged an initiative taken by Bojanala West Region in North West Province in involving Anglo Platinum and the University of Johannesburg in the training of all its teachers. The officials also acknowledged the workshops offered by Department of Basic Education, but they were uncomfortable with the inadequacy of these workshops. In probing as to what they meant exactly with the inadequacy of workshops it was realised that they were not happy that the workshops were short and not covering their training in-depth. As authors of this paper we can attest to this fact informed by our involvement in teacher training. That the in-service training of Technology Education teachers follows the same design as that of other subjects is undesirable considering the relative newness of Technology Education and that the subject is very practical in its pedagogical approach - design project and problem solving approach in pursuit of technological solutions to identified problems following non-linear process of investigation, design, make, evaluation and communication. It is thus our view that workshops are unnecessarily limited, thus breeding a shallow training of Technology Education teachers.

The educational officials also viewed the workshops that they attended as poorly organised. An educational official stated in this regard: "There are disappointments at times because teachers would be told to go back to schools as there is no Technology Education advisor to facilitate the training". Some TESAs stayed away from the training "due to their limited knowledge of Technology Education". It would appear that based on the incapacity of educational officials, they did not have the confidence to face the teachers; hence they rather chose to abscond from their training duties. This practice seemed frustrating to the teachers they even felt that universities could do a better job.

The next issue that was raised is the most difficult areas of technological knowledge that officials thought teachers needed training on - electrical, mechanical, pneumatic and hydraulic systems. The third issue had to do with the filling of senior posts. The subject advisors' specific response in this regard went as follows: "Teachers with training in Technology education should be given the priority to fill senior posts". However, the subject advisors might have not realized that there are not highly qualified teachers of Technology Education to can contest for the posts at that level.

\subsection{Resources}

The views of the educational officials about resources raised a variety of issues ranging from the needs of the officials themselves to the teachers' needs. The officials perceived transport as a resource issue to an extent that they felt "subject advisors must be provided with transport in order to perform their duties well". One of us (second author) is an educational official, thus he attests to the fact that officials use their own vehicles to run around discharging their duties. They are only required to claim for the kilometers that they travel. This could not go down well with the officials as they were using their families' "resources". The fact that the officials quickened to raise this issue could mean that they felt very uncomfortable with 
using their own cars to travel distances doing the work for Department of Basic Education, despite being reimbursed for the petrol costs.

The officials identified the second issue, which is a lack of equipment and Technology Education customised classrooms. In their responses they argued that Department of Basic Education should deliver on this matter. They pointed to the lack of tools and resources in schools, which made the teachers' job extremely difficult especially when considering that Technology Education is a theory-practice subject. A related issue raised by the officials is that most teachers were compelled by the situation of lack of resources to improvise, a recipe for discouragement on the side of the teachers. A least expected finding was about the teachers' attitude even though it logically followed from the frustration that the educational officials reckoned it impacted the teachers' motivation to teach Technology. According to the officials "teachers' attitudes towards Technology Education are negative due to the lack of resources and support, but positive for those that have resources and support". So, the Department of Education seems to be faced with a huge challenge to keep the volunteering Technology Education teachers in the teaching of the subject. The Technology Education officials are faced by this constraint because the Technology Education teachers constantly confronted them about this lack of resources. They felt that Department of Basic Education was running away from its responsibility to resource their schools by asking them to "improvise" or find materials via learners whom they should ask to bring cheap staff from home.

\subsection{Factors impeding the pedagogy of Technology Education}

The pedagogical issues that the educational officials raised centred on the factors that hinder the teaching of Technology. These factors were closely related to the issues of teacher training and resources. Resources surfaced again as the main factor. Resources actually drive the planning and teaching of the lesson, more so when taking into account the practical nature of Technology Education as a subject. The officials blamed the undesired pedagogy on the "lack of funding and procurement of resources". They thus insisted on the drawing up of a budget "to supply schools with the necessities". With further probing it turned out that by necessities they meant resources (equipment, textbooks and budget). Once again the officials wanted to see Department of Basic Education supplying the schools with tools and equipment as well as building special Technology Education classrooms. The implementation model that Department of Basic Education follows seems to be very much similar to that of the rest of other subjects even though Technology Education seriously suggests a resource dependent pedagogy.

Unsatisfactory Technology Education teacher training also resurfaced again as a hindering factor to the teaching of Technology. The officials felt that the training for teachers needed to be prioritised in order to ensure the proper teaching of Technology. "We need to start by training educators first" conveyed a strong meaning that teacher training was lacking direly. The provision of resource centres would help alleviate the problem of training as teachers would conveniently undergo training at the centres, especially if there would be a commitment from Department of Basic Education to resource the centres to make them conducive for such training. The training of officials was another added issue hampering the smooth teaching of Technology. The officials felt that the "undedicated support to train educational officials" as attributed to the ineffective management of "the national and provincial Technology projects". There was a need to appoint more education specialists to support schools. Specifically the HoDs needed the restructuring of each Area Project Office in such that it could be provided with its own subject advisor.

\section{Discussion of findings}

The findings of the study being reported in this paper reveal certain frustration experienced by the educational officials in the process of implementing the Technology Education curriculum. In terms of the findings of the study, the insufficient training of teachers of Technology, lack of resources and pedagogically related issues were the root cause of this frustration.

In terms of the findings, insufficient teacher training was the main hindrance to the implementation of Technology Education. It would appear that the training of Technology Education teachers, as perceived by the educational officials, was not properly designed so that it could provide a different and specialised equipping of these teachers. The theorypractice nature of Technology Education as a subject, and its relative newness in the curriculum suggest a different approach to teacher training. This constraint was compounded by the lack of commitment by the educational officials who were tasked to train the 
teachers. The deliberate stay away of the educational officials from the training of teachers had reference to their low levels of confidence informed by their ill preparation for the task - they were not well equipped themselves. This approach to the in-service teacher training can be likened to the blind made to lead the blind. The knowledge construct of Technology Education teachers seems rather shallow [8]. Reitsma and Mentz [8] reveal the areas of knowledge constructs exhibiting this incompetency in teachers - subject content knowledge and skills, pedagogical knowledge and skills and pedagogical content knowledge.

The inadequacy and shallowness of teacher training can be blamed on the training itself being too rapid and not properly resourced [5]. The appearance of Technology Education as a relatively newcomer in the national curriculum would not encourage this kind of approach to its implementation.

The officials also identified lack of resources as a constraint in the implementation of Technology Education. Resources make the curriculum implementation viable. It follows that the resourcelessness implementation of Technology Education is unfathomable. During their observation of teaching, interviews and document analysis, the findings of which they reported in their studies, Gumbo and Williams [17] noticed a dire lack of resources. Reitzma and Mentz [8] also observed the lack of resources especially in the rural schools. The findings revealed that both lack of resources and poor teacher training have a huge impact on the pedagogy of Technology Education.

\section{Conclusion}

The findings in this paper revealed the constraints that impede on the implementation of Technology Education. The views of the educational officials in response to the interview questions revealed these constraints - unsatisfactory Technology Education teacher training, lack of resources and the pedagogical factors that have a bearing on the implementation of Technology Education. We recommend that Department of Basic Education re-think the design of training for Technology Education teachers and educational officials. The fact that these teachers and officials were not trained at the roll-out of Technology Education strongly suggests that their training should be approached as a specialised and intensive training that incorporates exposure to industry. Building the knowledge construct of Technology Education in teachers who were asked to volunteer to teach
Technology should not be taken as a light enterprise. These teachers are fully qualified in other subject areas, but they are new learners of Technology since they were not trained before. The areas of the knowledge revealed above in the study by Reitsma and Mentz suggests the enormous work that should still be done in this regard. Department of Basic Education should invest in teacher training to ensure the successful implementation of Technology Education. There should be a commitment to resource schools to make them viable for the teaching of Technology. Added to this is a need for teacher resource centres. If the above recommendations are properly addressed by it will mean that pedagogical constraints are also taken care of.

\section{References}

[1] Department of Basic Education, Curriculum and Assessment Policy Statement. Draft. Government Printers, Pretoria, 2010.

[2] De Vries, M.J., An introduction to the philosophy of technology for non-philosophers, Springer, Dordrecht, 2005.

[3] C. Potgieter, The impact of the implementation of technology education on in-service teacher education in South Africa. International Journal of Technology and Design Education, Springer, New York, 2004, 14, pp. 205218.

[4] Y. Ono, and J. Ferreira, A case study of continuing teacher professional development through lesson study in South Africa. South African Journal of Education, University of North West, Potchefstroom, 2010, 30, pp. 59-74.

[5] Chisholm, L., A South African curriculum for the $21^{\text {st }}$ century: Report of the review committee on Curriculum 2005, Government Printers, Pretoria, 2000.

[6] T.A. Mapotse, and M.T. Gumbo, Identifying Grade 8 and 9 Technology teachers' areas of need for intervention in Limpopo Province. Journal of Social Sciences, Kamla-Raj, New Delhi, 2013, 36(1), pp. 19-28.

[7] Building the Capacities of Curriculum Specialists for Educational Reform, Designing and implementing local curricula Part III. http://www2.unescobkk.org/elib/publications/buildingcurricu lum/pt3.pdf (12 March 2014).

[8] G. Reitsma, and E. Mentz, Training of technology educators in South Africa: A model for short course inservice training. Presented at PATT18 Conference, Glascow, Scotland, 2007. 
[9] E.J. Rohaan, R. Taconis, and W.M.G. Jochems, Reviewing the relations between teachers' knowledge and pupils' attitude in the field of primary technology education, International Journal of Technology and Design Education, Springer, New York, 2008, www.springerlink.com/content./p020227247614xq7/?p=afce 429378144e17b4cbffdb33672fcb\&pi=16 (8 March 2014).

[10] L.S. Shulman, Knowledge and teaching: Foundations of the new reform. Harvard Educational Review, Harvard, Massachusetts, 1987, 57(1), pp. 1-21.

[11] Laine, S.W.M., and C. Otto, Professional development in education and the private sector: Following the leaders, North Central Regional Educational Laboratory, Oak Brook, IL, 2000.

[12] W. Feng, and K.W.M. Siu, Professional development for technology teachers in Mainland China and Hong Kong: Bridging theory and practice. Presented at the PATT22 Conference, Delft, Holland, 2009.

[13] Department of Basic Education, Report of the Task Team for the review of the implementation of the National Curriculum Statement, Government Printers, Pretoria, 2009.

[14] Malada, N.B. The continuous professional development of educators with regard to implementation of $O B E$ in the Limpopo Province, MEd Dissertation, Rand Afrikaans University, Johannesburg, 2004.

[15] V. Kumar, Promoting the application of science and technology to meet the millennium development goals, 2003. http://stdev.unctad.org/un/e-research.html (2 March 2014).

[16] J.P. Williams, and M.T. Gumbo, Discovering Technology teachers' pedagogical content knowledge: A comparative study between New Zealand and South Africa, Presented at PATT26 Conference. Stockholm, Sweden, 2012.

[17] Gumbo, M.T., and J.P. Williams, Technology teachers' pedagogical content knowledge: An exploratory study. Monograph, LAP Lambert, Saarbrücken, 2012.

[18] R.L. Breen, A practical guide to focus group research. Journal of Geography in Higher Education, Taylor \& Francis, Oxford, 2006, 30(3), pp. 463-475.

[19] Creswell, J.W., Qualitative inquiry and research design: Choosing among five approaches. SAGE, London, 2007.

[20] Gay, L.R., and P. Airasian, Educational research: Competencies for analysis and application. Sixth Edition, Prentice Hall, Merrill, 2000.

[21] McNeill, P. Research methods, Second Edition. Routledge, London, 1995. 